\title{
Stage IVB Nasal Cavity and Paranasal Sinus Cancer AJCC v8
}

National Cancer Institute

\section{Source}

National Cancer Institute. Stage IVB Nasal Cavity and Paranasal Sinus Cancer A/CC v8. NCI Thesaurus. Code C133081.

Stage IVB includes: (T 4b, Any N, M0); (Any T, N3, M0). T4b: Very advanced local disease. Tumor invades any of the following: orbital apex, dura, brain, middle cranial fossa, cranial nerves other than maxillary division of trig eminal nerve (V2), nasopharynx, or clivus. N3: Metastasis in a lymph node larger than $6 \mathrm{~cm}$ in greatest dimension and ENE(-); or metastasis in a single ipsilateral node larger than $3 \mathrm{~cm}$ in greatest dimension and ENE(+); or metastases in multiple ipsilateral, contralateral or bilateral nodes, any with ENE(+). M0: No distant metastasis. (AJCC 8th ed.) 